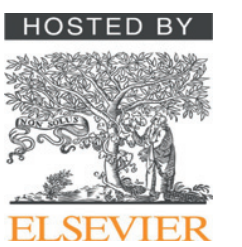

Short communication

\title{
Bilateral multiple coronary artery fistulae with angina pectoris and syncope
}

\author{
Elton Soydan *, Uğur Önsel Türk \\ ${ }^{a}$ Reyhanli Community Hospital, Hatay Turkey \\ b Bat Anadolu (Central) Hospital, Izmir Turkey
}

\section{A R T I C L E I N F O}

\section{Article history:}

Received 4 August 2015

Received in revised form 19 September 2015

Accepted 19 September 2015

Available online 28 September 2015

\section{Keywords:}

Coronary atery fistulae

Syncope

Angina

\begin{abstract}
A B S T R A C T
Coronary artery fistulae (CAF) are rare cardiac anomalies. They frequently arise from the right coronary artery (RCA) with fistulae originating from the left anterior descending artery (LAD) or from multiple arteries being less common. They do not usually cause symptoms and are incidentally diagnosed on routine cardiac imaging. We report a 70 years old male patient presenting with chest pain and syncope during physical activity. Diagnostic coronary angiography revealed bilateral multiple CAF originating from both the LAD and RCA. As high blood flow output was recognized in these large vascular anomalies contributing to 'steal phenomenon' surgical intervention was planned. This manuscript aimed to present the case and review the current literature for the management and treatment of these coronary anomalies.

(C) 2015 The Society of Cardiovascular Academy. Production and hosting by Elsevier B.V. All rights reserved. This is an open access article under the CC BY-NC-ND license (http://creativecommons.org/licenses/by-nc-nd/4.0/).
\end{abstract}

\section{Introduction}

A 70 year old male patient was admitted to our hospital as having typical chest pain and a syncope episode during climbing up the stairs of his apartment. He had experienced typical chest pain for about last one month. Syncope occurred while the patient was climbing up the stairs of his apartment. Prodromal symptoms were chest pain, pallor and dizziness. His relatives saw him recovering immediately after fainting. As he continued to have chest pain and dizziness an ambulance was called and brought to our hospital. He had not experienced any palpitations, involuntary contraction of the body and no urine and stool incontinence. He had been treated for hypertension and hyperlipidemia for about ten years. Ramipril $5 \mathrm{mg} / \mathrm{day}$ and Atorvastatin $20 \mathrm{mg} / \mathrm{day}$ were his daily medication. At admission he looked pale, his blood pressure was $110 / 80 \mathrm{mmHg}$ and electrocardiography showed a sinus rhythm with no ischemic signs and a heart rate of $117 / \mathrm{min}$ (Fig. 1).

Respiratory examination was unremarkable. During heart auscultation a continuous murmur of $3 / 6$ grade was heard all over the cardiac area. No carotid murmur was heard on auscultation. Carotid and vertebral artery doppler ultrasound examinations revealed no stenosis or plaque. His neurological examination and cranial computed tomography imaging were in normal limits. Neurology consultation stated no further neurologic tests for syncope. Abdominal examination was normal. No anemia or infection was found in his blood and urine tests contributing to sinus tachycardia. According to typical angina symptoms and 2013 European Society of Cardiology 'Guidelines in Myocardial Revascularization' a diagnostic coronary angiography was performed. After a single

\footnotetext{
* Corresponding author.

Peer review under responsibility of The Society of Cardiovascular Academy.
}

intracoronary injection of $25 \mathrm{ml}$ of radio opaque substance (Iopamidol), the distal portion of LAD was not visualized (Fig. 2). Contemporarily all of the large and multiple vascular anomalies originating from the proximal portion of LAD were dyed. This showed a high blood flow output through these vascular anomalies. During opaque injection into RCA multiple, thin lumened and tortuous vascular anomalies originating from the proximal portion of RCA were visualized (Fig. 3). Minimal plaque on RCA and LAD was detected. In order to find the drainage of these vascular anomalies a cardiac catheterization was performed. A step-up saturation was revealed in the right atrium and superior vena cava and Qp/Qs were calculated as 1.7:1. Their high blood flow output showed a 'steal phenomenon' and was considered as the cause of angina and syncope. Echocardiography showed a normal ejection fraction and a mild enlargement of the right ventricle with normal systolic pulmonary artery pressure and no valvular dysfunction. A 64 slice multidetector computed tomography (MDCT) showed multiple coronary artery fistulas originating both from LAD and RCA. Their erratic morphology and chaotic irregularity made their drainage location hard to be determined (Figs. 4-5). As a result we suggested the patient to have a surgical repair of these vascular anomalies causing ischemia and syncope. Although detailed explanation, patient refused surgical procedure and then an outpatient follow-up was decided. He was discharged with aspirine $100 \mathrm{mg} /$ day, atorvastatin $20 \mathrm{mg} /$ day, ramipril $5 \mathrm{mg} /$ day, metoprolol $25 \mathrm{mg} /$ day and was advised for prophylactic antibiotics for prevention of endocarditis.

\section{Discussion}

CAFs are rare congenital malformations that can be defined as direct vascular connections from a coronary artery to a cardiac chamber or 